\title{
Impact of the COVID-19 Pandemic on Pelvic and Acetabular Trauma: Experiences From a National Tertiary Referral Centre
}

Kunal Mohan ${ }^{1}$, Patrick McCabe ${ }^{1}$, Wafi Mohammed ${ }^{1}$, Justin M. Hintze ${ }^{1}$, Hasnain Raza ${ }^{1}$, Brendan O'Daly ${ }^{1}$, Michael Leonard ${ }^{1}$

1. Department of Trauma \& Orthopaedics, National Centre for Pelvic and Acetabular Surgery, Tallaght University Hospital, Dublin, IRL

Corresponding author: Kunal Mohan, kmohan@tcd.ie

\section{Abstract}

\section{Introduction}

The coronavirus disease 2019 (COVID-19) pandemic has had a significant impact on daily life. Restrictions imposed to help minimise virus transmission have limited both population movement and employment, as well as altering the potential mechanisms of high-energy trauma. The objective of this study was to assess the impact of the COVID-19 pandemic on pelvic and acetabular trauma.

\section{Materials and methods}

A retrospective observational study of the incidence, causality, patient profile, fracture morphology, and treatment strategy of pelvic and acetabular trauma managed in a national tertiary referral specialist pelvic and acetabular centre between the $1^{\text {st }}$ of March and $1^{\text {st }}$ of August 2020 was undertaken and compared to corresponding time periods in the two preceding years.

\section{Results}

A total of 78 patients were referred for management following pelvic and acetabular trauma during the study period with a mean age of 52 years (SD $+/-24.2$ ). Overall, $45 \%$ and $42 \%$ of patients were referred following isolated pelvic or acetabular fractures respectively. The most frequent mechanism of injury was a fall from height $(>1 \mathrm{~m})(42 \%)$, with $53 \%$ of patients suffering from concomitant injuries and $32 \%$ requiring surgical management. While there was a statistically significant difference in mechanism of injury $(\mathrm{P}=0.026)$, there was no significant difference in overall incidence, fracture types, incidence of concomitant injuries, or overall proportion requiring surgical intervention during the study period when compared to previous years.

\section{Conclusion}

Review began 05/09/2021 Review ended 06/09/2021 Published 06/22/2021

\section{○ Copyright 2021}

Mohan et al. This is an open access article distributed under the terms of the Creative Commons Attribution License CC-BY 4.0., which permits unrestricted use, distribution, and reproduction in any medium, provided the original author and source are credited.
While some variation in the mechanisms of injury have been observed, the overall incidence, patient, fracture, and injury profiles associated with pelvic and acetabular trauma appear to have remained consistent during the COVID-19 pandemic. Additionally, the number and proportion of those requiring surgical treatment of these fractures have remained stable. Understanding the continued burden of these potentially severe injuries may help guide injury prevention, treatment, and resource allocation as the pandemic continues.

Categories: Orthopedics, Public Health, Trauma

Keywords: pelvis, fracture, covid-19, pandemic, trauma, acetabulum

\section{Introduction}

The novel severe acute respiratory syndrome coronavirus 2 (SARS-CoV-2) coronavirus disease 2019 (COVID19) outbreak has resulted in one of the most profound healthcare challenges encountered in modern-day medicine [1]. Presumed to have originated in Wuhan, China, this respiratory disease was first reported in December 2019 and the subsequent widespread spread of cases worldwide resulted in the declaration of the COVID-19 outbreak as a global pandemic on the 11th of March 2020 [2].

Across the world, nationwide-specific approaches to both help limit the spread of COVID-19 within the community and to prevent both virus transmission as well as health systems from being overwhelmed by potentially increased demand created by the pandemic have been instigated [3]. In a societal context, these restrictions have significantly altered the manner in which people undertake their occupations, with many restricted solely to working from home at the height of restrictions [3,4]. Additionally, limitations on both international and national travel in attempts to curb transmission of COVID-19 have occurred to varying degrees and have impacted typical population mobility patterns [5]. Alterations to other aspects of life such 
as population gatherings, sporting, cultural, education and retail activities also occurred as part of the global response to COVID-19 [4], with the cumulative effect of all of these alterations being a definite impact on day to day population behaviour [6].

As a result of these changes, COVID-19 has had a tangible effect on current orthopaedic practice [7]. While re-prioritisation of elective orthopaedic at the height of the pandemic made up a part of initial systemic responses to COVID-19 [7], an alteration in both the volume and type of orthopaedic trauma encountered in daily practice was also predicted due to the anticipated alterations in typical population activity as a result of COVID-19 restrictions [8]. As the number of COVID-19 patients increased, management of orthopaedic trauma underwent reorganisation so to maximise both patient and staff safety and minimise the spread of the virus [9]. While orthopaedic trauma has continued to occur during the pandemic, an overall reduction in both the number of trauma patients, number of referrals to orthopaedic trauma services and number of orthopaedic admissions have been described in the current literature [10-12]. In addition, significant reductions in the overall number of orthopaedic operations undertaken have been identified [13]. An alteration in the typical mechanisms of orthopaedic trauma has also been witnessed, with reductions in the number of overall orthopaedic hospital admissions and referrals to the trauma emergency departments following both road traffic accidents (RTAs) and workplace incidents identified during the initial COVID-19 period $[12,14]$. Contrastingly, an increase in do-it-yourself (DIY) construction, falls from height and domestic-related injuries during COVID-19 restrictions have also been described [14,15].

While an overall alteration in orthopaedic trauma volume appears to have been observed during the peak of the COVID-19 pandemic $[8,10,12,13]$, the trends for specific trauma subtypes appear to vary, with no statistically significant change in the operative incidence of periprosthetic fractures, soft tissue injuries, open fractures or spinal cord injuries identified in several studies $[8,10,13]$. Conversely, a statistically significant reduction in operative volume has been identified in lower limb fractures and simple fracture patterns [10], with differing results in regards to the incidence of both hip and upper limb fractures observed during the pandemic to date $[8,10,12,13]$.

Pelvic and acetabular trauma constitutes between 3\% and $8 \%$ of all fractures managed in the acute orthopaedic trauma setting, with an ever increasing incidence of these fractures encountered in modern-day practice [16]. Typically bimodal in age distribution [17], these fractures are associated with both significant morbidity and complications, particularly when requiring surgical treatment $[18,19]$. Due to the often complex nature of these fractures when occurring either in isolation or in the context of the high-energy polytraumatised patient, definitive management involving specialist treatment centres following initial stabilisation is recommended to help improve outcomes [20]. As a result, management of these fractures require significant resources and are thus associated with substantial direct and indirect costs to patients, the healthcare system and society alike [21].

While the burden of pelvic and acetabular trauma is potentially significant, there is to our knowledge a relative paucity of evidence to date evaluating the specific impact of the ongoing COVID-19 pandemic on pelvic and acetabular fractures at a national level. The objective of this study was, therefore, to quantify whether there has been any alteration in both the incidence of pelvic and acetabular fractures and the proportion requiring surgical treatment as a result of the pandemic, as well as to identify any potential effect that the pandemic has had on the patient, fracture and injury profiles typically associated with these types of trauma.

\section{Materials And Methods}

A retrospective, observational, single-centre study of patients sustaining pelvic and acetabular fractures was undertaken. This study was carried out in a national centre for pelvic and acetabular surgery, which serves as the solitary national tertiary referral specialist hospital centre for management of these injuries in the Republic of Ireland, receiving referrals nationwide from all hospitals managing acute orthopaedic trauma. Ethical approval was obtained from the hospital's Research and Ethics Committee.

Patients referred for assessment for management of pelvic and acetabular fractures sustained between the $1^{\text {st }}$ of March 2020 and $1^{\text {st }}$ of August 2020 were identified through a prospectively maintained departmental referral database and deemed suitable for inclusion as the study group. Patients who suffered their index injuries outside of this time period were excluded from this study. This time period was selected to broadly correspond to the initial phases of the national response introduced following the start of the COVID-19 pandemic, with the first case of COVID-19 diagnosed nationally on the 29th of February 2020 [4]. Additionally, patients referred following pelvic and acetabular fractures sustained during the corresponding time period in both 2019 and 2018 were also identified through the same departmental referral database for inclusion as control groups for the purposes of comparison.

Between the 1st of March and 1st of August 2020, six distinct phases of national restrictions were instituted in response to the COVID-19 pandemic [4]. Each of these phases placed different limitations upon widespread aspects of society including but not limited to internal travel, economic activity and population gatherings and are broadly described in Table 1 [4]. Patients suitable for inclusion during the study period in 
2020 were additionally subdivided by their temporal correspondence to specific restriction subphase.

\begin{tabular}{|c|c|c|c|c|c|}
\hline $\begin{array}{l}\text { Governmental } \\
\text { Phase [4] }\end{array}$ & Dates & National Travel Activity & Economic Activity & Social Activity & $\begin{array}{l}\text { Commercial/ } \\
\text { Educational } \\
\text { Activity }\end{array}$ \\
\hline $\begin{array}{l}\text { Containment } \\
\text { Phase }\end{array}$ & $\begin{array}{l}1^{\text {st }}- \\
12^{\text {th }} \text { March }\end{array}$ & No restrictions. & No restrictıons. & $\begin{array}{l}\text { Self-isolation if } \\
\text { symptomatic, contact } \\
\text { tracing. }\end{array}$ & No restrictions. \\
\hline Delay Phase & $\begin{array}{l}12^{\text {th }}- \\
27^{\text {th }} \text { March }\end{array}$ & No restrictions. & $\begin{array}{l}\text { Reduction of workplace } \\
\text { contacts, work from home if } \\
\text { possible. }\end{array}$ & $\begin{array}{l}\text { Gatherings } \leq 50 \\
\text { people indoor, } \leq 200 \\
\text { outdoor. }\end{array}$ & $\begin{array}{l}\text { Closure of } \\
\text { educational } \\
\text { institutions. }\end{array}$ \\
\hline $\begin{array}{l}\text { Stay at Home } \\
\text { Phase }\end{array}$ & $\begin{array}{l}27^{\text {th }} \text { March- } \\
18^{\text {th }} \text { May }\end{array}$ & $2 \mathrm{~km}$ radius from home. & $\begin{array}{l}\text { Essential work only otherwise } \\
\text { work from home. }\end{array}$ & $\begin{array}{l}\text { Gatherings outside of } \\
\text { living unit prohibited. }\end{array}$ & $\begin{array}{l}\text { Only essential } \\
\text { retail open. }\end{array}$ \\
\hline $\begin{array}{l}\text { Easing of } \\
\text { Restrictions: } \\
\text { Phase } 1\end{array}$ & $\begin{array}{l}18^{\text {th }} \text { May- } \\
8^{\text {th }} \text { June }\end{array}$ & $5 \mathrm{~km}$ radius from home. & $\begin{array}{l}\text { Return of outdoor work } \\
\text { otherwise work from home. }\end{array}$ & $\begin{array}{l}\text { Gatherings } \leq 4 \text { people } \\
\text { outdoors only. }\end{array}$ & $\begin{array}{l}\text { Only essential \& } \\
\text { outdoor retail } \\
\text { open. }\end{array}$ \\
\hline $\begin{array}{l}\text { Easing of } \\
\text { Restrictions: } \\
\text { Phase } 2\end{array}$ & $\begin{array}{l}8^{\text {th }} \text { June- } \\
29^{\text {th }} \text { June }\end{array}$ & $\begin{array}{l}\text { Within county of } \\
\text { residence or } 20 \mathrm{~km} \text { radius } \\
\text { from home. }\end{array}$ & $\begin{array}{l}\text { Return to work if needed } \\
\text { otherwise work from home. }\end{array}$ & $\begin{array}{l}\text { Gatherings } \leq 4 \text { people } \\
\text { indoors, } \leq 15 \\
\text { outdoors. }\end{array}$ & $\begin{array}{l}\text { All retail } \\
\text { reopened. }\end{array}$ \\
\hline $\begin{array}{l}\text { Easing of } \\
\text { Restrictions: } \\
\text { Phase } 3\end{array}$ & $\begin{array}{l}29^{\text {th }} \text { June- } \\
1^{\text {st }} \text { August }\end{array}$ & No restrictions. & $\begin{array}{l}\text { Return to work if needed } \\
\text { otherwise work from home. }\end{array}$ & $\begin{array}{l}\text { Gatherings } \leq 50 \\
\text { people indoors, } \leq 200 \\
\text { outdoors. }\end{array}$ & $\begin{array}{l}\text { All retall } \\
\text { reopened. }\end{array}$ \\
\hline
\end{tabular}

TABLE 1: Generalised Summary of National Governmental 2020 COVID-19 Restrictions

Demographic data recorded for those suitable for inclusion in either the study group (2020) or comparison groups (2019 and 2018) contained original referral hospital location, date of injury, gender and age. Patients underlying medical status was quantified using the American Society of Anaesthesiologists Physical Status Scale (ASA-PS). The primary study outcomes were extrapolated from the departmental referral database, medical notes and accompanying radiological investigations and are outlined in Table 2.

\section{Primary Outcomes}

\section{Total Number of Referrals}

Total Number of Referrals Requiring Surgery

Fracture Pattern: Isolated Pelvic Ring, Isolated Acetabulum, Combined Pelvis \& Acetabulum, Isolated Ilium, Isolated Sacrum
$\%$ of Total Referrals Requiring Surgery
$\%$ Presenting with Concomitant Injuries

Mechanism of Injury: Road Traffic Accident (RTA), High-Energy Fall from Height, Low-Energy Fall from Standing, Crush Injury, Atraumatic

TABLE 2: Recorded Primary Data Outcomes

The above information was recorded into an electronic database and divided into three distinct time periods (March-August 2020, March-August 2019 and March-August 2018 respectively). Those referred in 2020 were also subdivided by national restriction subphase.

Assessment of the recorded data included both qualitative and quantitative analysis. Descriptive statistics for qualitative analysis included number (n), percentage (\%), mean and standard deviation (SD), allowing for both illustration of trends and comparison of the study group referred in 2020 to the two preceding control years as well as by national restriction subphase within 2020 itself. 


\section{Cureus}

Quantitative analysis was undertaken using Statistical Package for the Social Sciences (SPSS) version 26 (IBM Corp, Armonk, NY) with a P value of $<0.05$ considered statistically significant. Comparison of the overall number of referrals, number of referrals undergoing surgical treatment and the proportion of those referred requiring surgical intervention was compared between the study group (2020) and two control groups (2019 and 2018) through a one-way analysis of variance (ANOVA). Evaluation of potential difference in the mechanism of injury, types of fractures and incidence of concomitant injuries in those referred between the study group (2020) and two control groups (2019 and 2018) was undertaken using crosstabulation and chi-square analysis, with additional post-hoc analysis using Bonferroni correction to detect differences in column proportions in those outcomes displaying statistically significant differences.

\section{Results}

Overall, 78 patients were referred for assessment for the management of their pelvic and acetabular fractures to the national centre during the study period of $1^{\text {st }}$ March to $1^{\text {st }}$ August 2020, with a corresponding rate of 0.51 pelvic and acetabular fracture referrals to the national centre per day. Of those included, 53 were males and 25 females at a male:female ratio of $68 \%$ to $32 \%$, with an overall mean age of 52 years (SD +/- 24.2) (Table 3). Division of those referred in 2020 by subphase of national restrictions is further illustrated in Table 4. Overall ASA-PS grading of those included showed a predominance of either healthy patients or those with mild underlying systemic disease, with $85 \%(\mathrm{n}=66)$ identified as either ASA-PS I or II (Table 5).

\begin{tabular}{|c|c|c|c|}
\hline Characteristics & 2020 & 2019 & 2018 \\
\hline Total Number of Pelvic \& Acetabular Referrals & 78 & 59 & 88 \\
\hline Number of Referrals/Day & 0.51 & 0.39 & 0.58 \\
\hline Mean Age of Referrals (Years) & 52 & 53 & 52 \\
\hline Male:Female Ratio & $68: 32$ & 63:37 & $66: 34$ \\
\hline$\%$ of Referrals with Concomitant Injuries & $53 \%$ & $37 \%$ & $53 \%$ \\
\hline Number of Referrals Requiring Surgery & 25 & 32 & 36 \\
\hline Number of Surgeries/Day & 0.16 & 0.21 & 0.24 \\
\hline$\%$ of Total Referrals Requiring Surgery & $32 \%$ & $54 \%$ & $41 \%$ \\
\hline
\end{tabular}

TABLE 3: Hospital Indicators and Patient Demographic Characteristics by Year

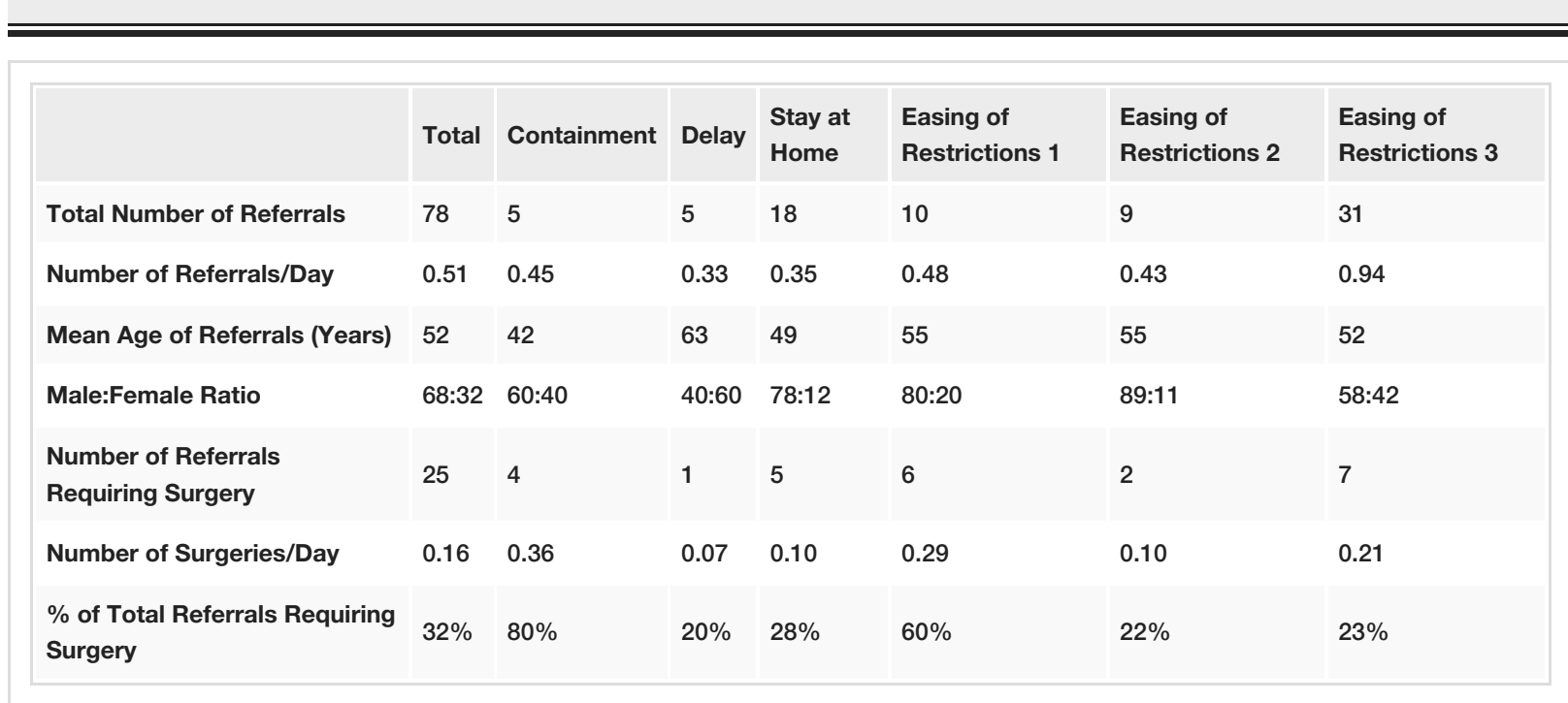

TABLE 4: Included 2020 Patient Demographics by Governmental Phase 


\section{Cureus}

\begin{tabular}{|c|c|c|c|}
\hline & 2020 & 2019 & 2018 \\
\hline ASA-PS I & $59 \%$ & $59 \%$ & $51 \%$ \\
\hline ASA-PS II & $26 \%$ & $29 \%$ & $23 \%$ \\
\hline ASA-PS III & $10 \%$ & $10 \%$ & $26 \%$ \\
\hline ASA-PS IV & $5 \%$ & $2 \%$ & $0 \%$ \\
\hline
\end{tabular}

\section{TABLE 5: \% Included Patient ASA-PS Classification by Year}

ASA-PS: American Society of Anaesthesiologists Physical Status Scale.

Comparatively, 59 and 88 patients were referred for assessment for the management of pelvic and acetabular fractures between the 1st of March and $1^{\text {st }}$ of August in 2019 and 2018, respectively. One-way ANOVA analysis showed no statistical difference in the overall number of referrals in each year $(\mathrm{P}=0.204)$

(Table 6). The number of referrals per month across all three years is further illustrated in Figure 1.

\begin{tabular}{|c|c|c|c|c|}
\hline & 2020 & 2019 & 2018 & P-Value \\
\hline Total Number of Referrals & 78 & 59 & 88 & 0.204 \\
\hline Total Number of Referrals undergoing Surgery & 25 & 32 & 36 & 0.642 \\
\hline$\%$ of Total Referrals undergoing Surgery & $32 \%$ & $54 \%$ & $41 \%$ & 0.405 \\
\hline
\end{tabular}

TABLE 6: One-Way ANOVA Statistical Analysis of Hospital Indicators by Year

ANOVA: analysis of variance.

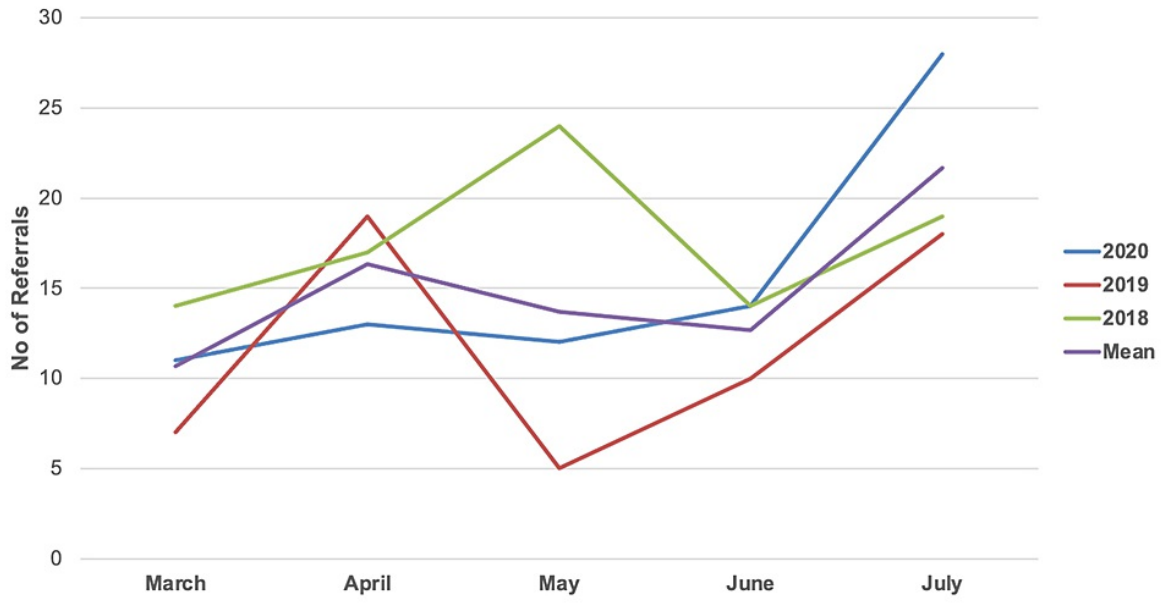

FIGURE 1: Total Number of Referred Patients by Month

In 2019, the overall mean age of those referred was 53 (SD+/-22.8), with $63 \%(n=37)$ of these males and $37 \%$ $(n=22)$ of these females, reflecting the profile of patients referred in 2020. Similarly, the mean age of those referred in 2018 was $52(\mathrm{SD}+/-22.0)$, with $66 \%(\mathrm{n}=58)$ and $34 \%(\mathrm{n}=30)$ of those suitable for inclusion male and female respectively, again resembling the profile of those referred in 2020. The underlying medical status of those referred in 2020 was also comparable to that witnessed in both 2019 and 2018, with 86\% $(n=52)$ and $74 \%(n=65)$ of patients either ASA-PS I or II in 2019 and 2018, respectively. Further descriptive comparison of referred patient profiles in between the study group and two control groups can be found in Table 3 and Table 5. 


\section{Cureus}

In 2020, the most common causative mechanism of injury was following a high-energy fall from height, occurring in $42 \%$ ( $n=33$ ) of patients. This was followed by RTAs ( $23 \%, n=18)$, low-energy falls from standing $(21 \%, n=16)$ and crush injuries (14\%, $n=11)$. However, the most common mechanism of injury in 2019 was either a low-energy fall from standing or a crush injury (each $27 \%, n=16)$, with RTA $(34 \%, n=30)$ the most common causative mechanism of injury in 2018. Overall illustration of mechanism of injury by \% of total referrals per year is illustrated in Figure 2. Chi-squared analysis of column proportions showed a statistically significant difference in the proportion of mechanism of injury between each year $(p=0.026)$, with additional post hoc analysis showing a statistically significant higher proportion in falls from height during the 2020 study period when compared to 2019 ( $\mathrm{p}<0.05$ ).

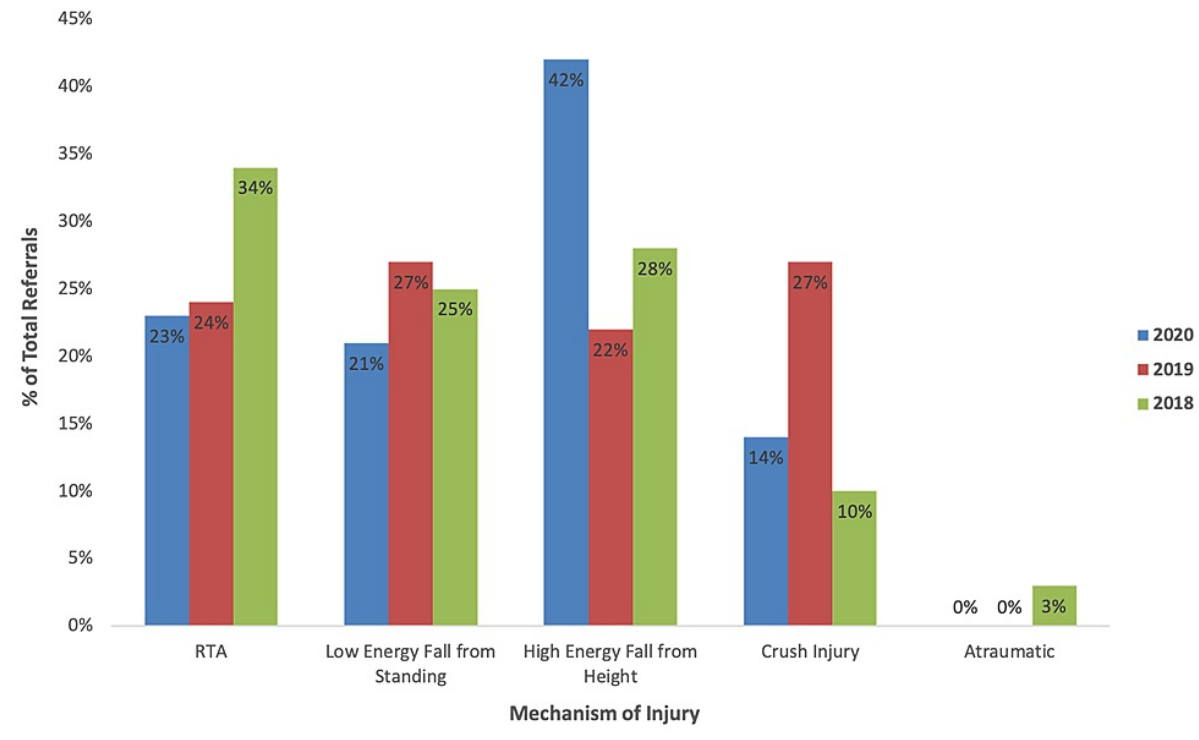

FIGURE 2: Mechanism of Injury by Year

Isolated fractures of the pelvic ring were the most predominant fracture type referred in 2020, occurring in $45 \%(n=35)$ of referrals. This was followed by isolated acetabular fractures, which occurred in $42 \%(n=33)$ of referrals. Combined pelvis and acetabular fractures, isolated ilium fractures and isolated sacrum fractures made up $6 \%$ ( $\mathrm{n}=$ five), $5 \%$ ( $\mathrm{n}=$ four) and $2 \%$ ( $\mathrm{n}=$ one) of referrals encountered in 2020 , respectively. Comparably, the most frequent fracture type encountered in 2019 were isolated pelvic ring fractures ( $53 \%$, $\mathrm{n}=31)$ and isolated acetabular fractures $(42 \%, \mathrm{n}=25)$, with isolated pelvic ring and acetabular fractures each occurring in $43 \%(n=38)$ of referrals in 2018. A summary of the types of fractures encountered in each year is further illustrated in Figure 3. Chi-squared analysis of column proportions showed no statistically significant difference in the types of fractures encountered between each year $(\mathrm{p}=0.731)$.

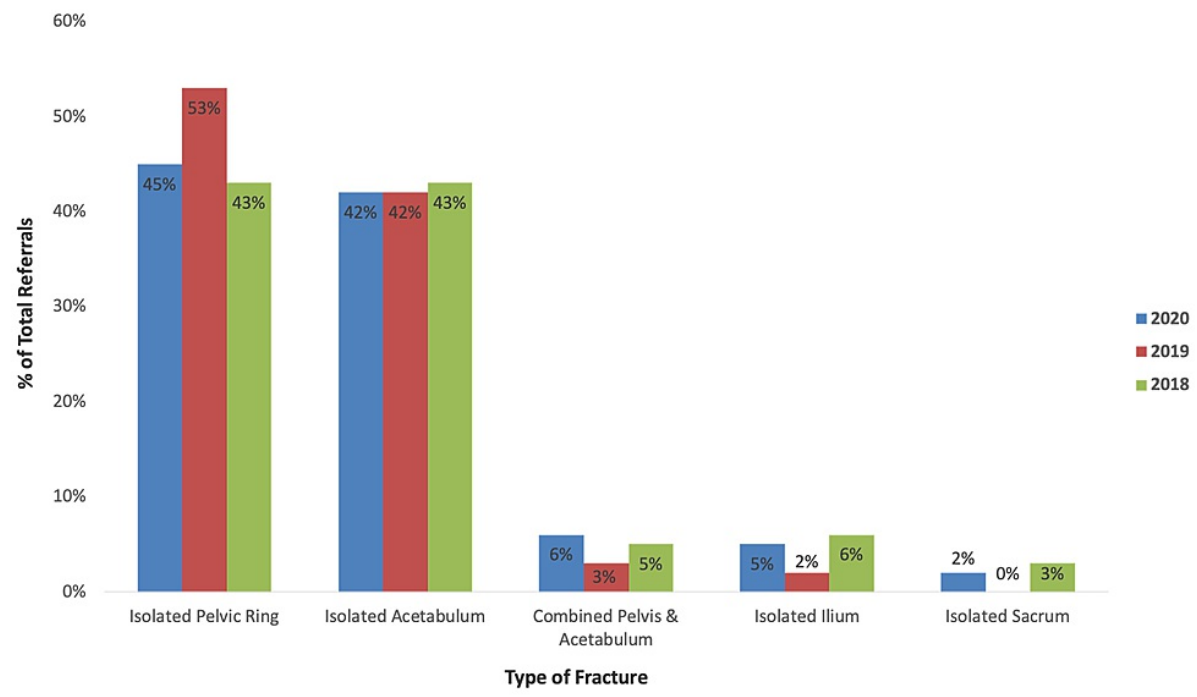

FIGURE 3: Type of Fracture by Year 
Concomitant skeletal or visceral injuries to the referred pelvic and acetabular fractures were detected in $53 \%$ $(n-41)$ of patients referred in 2020, with $37 \%(n=22)$ and $53 \%(n=47)$ of patients suffering from concomitant injuries in 2019 and 2018, respectively (Table 3). Overall, chi-squared analysis of column proportions showed no statistically significant difference in the proportion of patients sustaining concomitant injuries to their referred pelvic and acetabular fractures $(\mathrm{p}=0.115)$.

Of the total number of patients referred following pelvic and acetabular fractures in 2020, 32\% (n=25) required transfer and admission for surgical intervention following assessment. The overall surgical rate per day in 2020 was 0.16 (as seen in Table 3), with division of those operated upon in 2020 further divided by subphase of national restrictions in Table 4. In 2019 and 2018, 54\% $(n=32)$ and 41\% $(n=36)$ of total referrals required admission for surgical referral respectively. One-way ANOVA analysis showed no statistical difference in both the overall number of patients requiring surgical intervention (0.642) or the proportion of patients referred requiring surgery $(\mathrm{p}=0.405)$ between each year (Table 6$)$. The number of patients requiring surgical intervention per month across all three years are further illustrated in Figure 4.

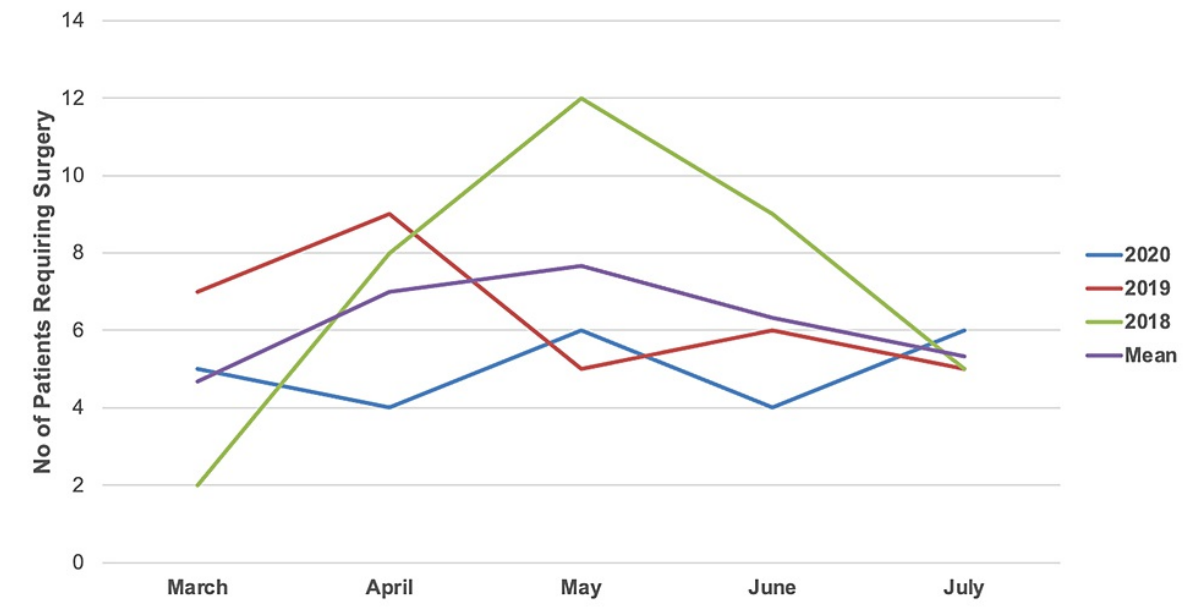
FIGURE 4: Total Number of Referred Patients Requiring Surgery by
Month

\section{Discussion}

COVID-19 has had an effect on the amount of trauma encountered in orthopaedic practice, with difference in the volume managed during COVID-19 when compared to previous years described in the literature $[8,10,12,13]$. Variations in the type of trauma exposure have also been reported, with increased rates of domestic-related injuries and decreased RTA and sports-related injuries described $[14,22,23]$. A combination of increased time restricted to home, seasonal weather changes, and an increase in DIY activities during COVID-19 lockdown has been described as being associated with a significant incidence in domestic-related traumatic events, with a particular prominence of falls from height such as ladders as a result of these behavioural changes [14,23].

A similar pattern appears to also occur in those suffering from pelvic and acetabular fractures, with the most important findings of this study identifying both a statistically significant difference in the types of mechanism of injury between each year and a statistically higher proportion of falls from height during the COVID-19 pandemic period when compared to the previous year, with falls from height the most frequent mechanism of injury precipitating in pelvic and acetabular fractures during the COVID-19 pandemic study period.

While there appears to have been an alteration in the mode of injury precipitating in pelvic and acetabular fractures during the pandemic identified in this study, there was no statistically significant difference in the overall incidence of patients referred for management of pelvic and acetabular fractures during the pandemic in this study when compared to prior years. Additionally, the encountered patient profile in regards to age, gender, and comorbid statuses seen in those sustaining pelvic and acetabular fractures during COVID-19 appeared comparable to both that witnessed in previous years as well as trends previously identified of those sustaining traumatic injuries nationally [24].

Similarly, there appears to be no significant difference in the types of pelvic and acetabular fractures encountered during COVID-19 in this study, with the proportion of each fracture type appearing relatively consistent across each year. There was also comparable incidence of concomitant injuries in those referred for management of their pelvic and acetabular fractures, allowing for inference that while the type of 


\section{Cureus}

traumatic insult may have altered during COVID-19, the degree and significance of injuries causing these types of fractures continue to persist, with the existence of other concomitant injuries being poorly prognostic for successful outcomes following these potentially severe fractures [25]. This hypothesis is further strengthened by the findings that during the COVID-19 study period, a comparable volume and proportion of all pelvic and acetabular fractures referred for assessment to the national centre in this study continued to require surgical treatment so as to best optimise outcomes (Figure 5).

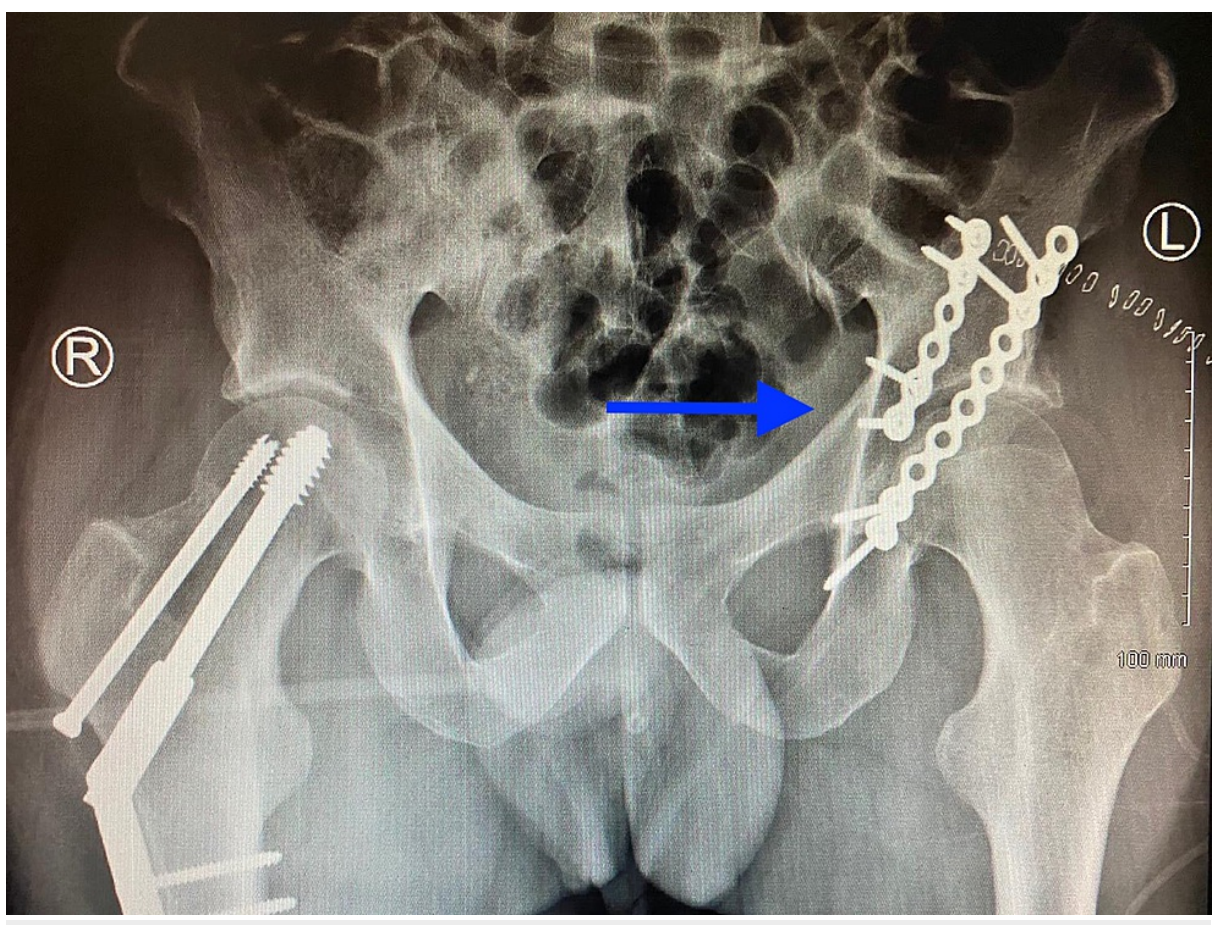

\section{FIGURE 5: Plain Radiographic Example of a Left Acetabular Fracture Sustained During the COVID-19 Pandemic Requiring Surgical Fixation}

As the COVID-19 pandemic continues, understanding of the resultant alterations in all facets of medicine will allow for stratification of the healthcare response and permit more effective management of further waves of the virus [26]. Pelvic and acetabular fractures are typically complex and significant injuries, often requiring substantial resources and specialist input so to maximise patient outcomes and minimise potential complications [18-20]. While there appears to have been an alteration in the mode of injury precipitating these fractures during the pandemic within the context of imposed societal restrictions, the overall proportion of pelvic and acetabular fractures managed appears to have remained consistent. Given the potentially significant sequelae of these injuries [18-20], understanding of the persistent burden of these injuries during this pandemic may help guide resource allocation and optimise trauma so as to insure optimal treatment of these injuries [14,27], particularly in regards maximising expedient and specialised care within the context of attempting to minimise virus transmission.

Additionally, further understanding of the COVID-19 associated variations in precipitating injury patterns previously outlined in published orthopaedic literature $[12,14,15,22,23]$ is of benefit in raising awareness and reducing the risk of further injury, particularly in regards to falls from height in the domestic setting [14]. While limitations to our study exist in regards to sample size, its retrospective design and potential for referral severity bias to the national centre for management of pelvic and acetabular fractures, we believe this study to be of importance as it allows reporting of the impact of the pandemic at a national level on these potentially severe injuries, thus possibly help guide future understanding of pelvic and acetabular fractures as the COVID-19 pandemic continues.

\section{Conclusions}

While some variation in the causative mechanisms of injury has been observed, the overall incidence, patient, fracture, and injury profiles associated with pelvic and acetabular trauma appear to have remained consistent during the COVID-19 pandemic. Furthermore, the number and proportion of those requiring surgical treatment of these fractures have remained stable. Understanding the persistent burden of these potentially severe injuries during the global pandemic may help guide injury prevention, treatment, and resource allocation during the course of the pandemic, as well as help guide further epidemiological study of the variation in orthopaedic trauma encountered during this period as our understanding of the impact of COVID-19 continues to develop. 


\section{Additional Information \\ Disclosures}

Human subjects: Consent was obtained or waived by all participants in this study. SJH/TUH Research Ethics Committee issued approval REC: 2021-01 Chairman's Action (01). 04th January 2021 REF: The Impact of COVID-19 on Pelvic and Acetabular Trauma: Experiences from a National Tertiary Referral Centre REC: 2021-01 Chairman's Action (01) (Please quote reference on all correspondence) Date of Valid Submission to REC: 22.11.2020 Date of Ethical Review: 14.12.2020 Dear Dr Mohan, The Chairman, Prof. Richard Deane, on behalf of the Research Ethics Committee, has reviewed correspondence you submitted to the SJH/TUH JREC and has given FULL APPROVAL for the above named study to proceed. The following documents were reviewed: $\boldsymbol{\nabla}$ Standard Application Form Please note that ethical approval for this study is only active under the following conditions: 1 . Applicants must submit an annual report for ongoing projects. 2 . Applicants must submit an end of study declaration/end of study report upon completion of the study. 3 . All adverse events must be reported to the JREC. 4 . All changes (minor and substantial) to documentation/study must be submitted to the JREC using the amendment request form and the changes must be tracked/highlighted clearly. Approval from the JREC is required before implementation of the changes. Yours sincerely, REC Officer - Dr Sadhbh O’Neill SJH/TUH Research Ethics Committee. Animal subjects: All authors have confirmed that this study did not involve animal subjects or tissue. Conflicts of interest: In compliance with the ICMJE uniform disclosure form, all authors declare the following: Payment/services info: All authors have declared that no financial support was received from any organization for the submitted work. Financial relationships: All authors have declared that they have no financial relationships at present or within the previous three years with any organizations that might have an interest in the submitted work. Other relationships: All authors have declared that there are no other relationships or activities that could appear to have influenced the submitted work.

\section{References}

1. Pascarella G, Strumia A, Piliego C, et al.: COVID-19 diagnosis and management: a comprehensive review . J Intern Med. 2020, 288:192-206. 10.1111/joim.13091

2. Cucinotta D, Vanelli M: WHO declares COVID-19 a pandemic . Acta Biomed. 2020, 91:157-60. 10.23750/abm.v91i1.9397

3. Han E, Tan MMJ, Turk E, et al.: Lessons learnt from easing COVID-19 restrictions: an analysis of countries and regions in Asia Pacific and Europe. Lancet. 2020, 396:1525-34. 10.1016/S0140-6736(20)32007-9

4. Kennelly B, O'Callaghan M, Coughlan D, et al.: The COVID-19 pandemic in Ireland: an overview of the health service and economic policy response. Health Policy Technol. 2020, 9:419-2. 10.1016/j.hlpt.2020.08.021

5. Chinazzi M, Davis JT, Ajelli M, et al.: The effect of travel restrictions on the spread of the 2019 novel coronavirus (COVID-19) outbreak. Science. 2020, 368:395-400. 10.1126/science.aba9757

6. Pedrosa AL, Bitencourt L, Fróes ACF, Cazumbá MLB, Campos RGB, de Brito SBCS, Simões E Silva AC: Emotional, behavioral, and psychological impact of the COVID-19 pandemic . Front Psychol. 2020, 11:566212. 10.3389/fpsyg.2020.566212

7. Mackay ND, Wilding CP, Langley CR, Young J: The impact of COVID-19 on trauma and orthopaedic patients requiring surgery during the peak of the pandemic: a retrospective cohort study. Bone Jt Open. 2020, 1:5209. 10.1302/2633-1462.19.BJO-2020-0108.R1

8. Elbardesy H: Impact of the COVID-19 pandemic on trauma and orthopaedic service in the Republic of Ireland. EMJ Microbiol Infect Dis. 2020, 10.33590/emjmicrobiolinfectdis/20-00116

9. Placella G, Salvato D, Delmastro E, Bettinelli G, Salini V: CoViD-19 and ortho and trauma surgery: the Italian experience. Injury. 2020, 51:1403-5. 10.1016/j.injury.2020.04.012

10. Murphy T, Akehurst H, Mutimer J: Impact of the 2020 COVID-19 pandemic on the workload of the orthopaedic service in a busy UK district general hospital. Injury. 2020, 51:2142-7. 10.1016/j.injury.2020.07.001

11. Waseem S, Nayar SK, Hull P, Carrothers A, Rawal J, Chou D, Khanduja V: The global burden of trauma during the COVID-19 pandemic: a scoping review. J Clin Orthop Trauma. 2021, 12:200-7. 10.1016/j.jcot.2020.11.005

12. Nuñez JH, Sallent A, Lakhani K, Guerra-Farfan E, Vidal N, Ekhtiari S, Minguell J: Impact of the COVID-19 pandemic on an emergency traumatology service: experience at a tertiary trauma centre in Spain. Injury. 2020, 51:1414-8. 10.1016/j.injury.2020.05.016

13. Wong JSH, Cheung KMC: Impact of COVID-19 on orthopaedic and trauma service: an epidemiological study . J Bone Joint Surg Am. 2020, 102:e80. 10.2106/JBJS.20.00775

14. Fahy S, Moore J, Kelly M, Flannery O, Kenny P: Analysing the variation in volume and nature of trauma presentations during COVID-19 lockdown in Ireland. Bone Jt Open. 2020, 1:261-6. 10.1302/20463758.16.BJO-2020-0040.R1

15. Hampton M, Clark M, Baxter I, Stevens R, Flatt E, Murray J, Wembridge K: The effects of a UK lockdown on orthopaedic trauma admissions and surgical cases: a multicentre comparative study. Bone Jt Open. 2020, 1:137-43. 10.1302/2633-1462.15.BJO-2020-0028.R1

16. Rinne PP, Laitinen MK, Kannus P, Mattila VM: The incidence of pelvic fractures and related surgery in the Finnish adult population: a nationwide study of 33,469 patients between 1997 and 2014. Acta Orthop. 2020, 91:587-92. 10.1080/17453674.2020.1771827

17. Ferguson TA, Patel R, Bhandari M, Matta JM: Fractures of the acetabulum in patients aged 60 years and older: an epidemiological and radiological study. J Bone Joint Surg Br. 2010, 92:250-7. 10.1302/0301620X.92B2.22488

18. Giannoudis PV, Grotz MR, Papakostidis C, Dinopoulos H: Operative treatment of displaced fractures of the 


\section{Cureus}

acetabulum: a meta-analysis. J Bone Joint Surg Br. 2005, 87:2-9. 10.1302/0301-620X.87B1.15605

19. Guthrie HC, Owens RW, Bircher MD: Fractures of the pelvis. J Bone Joint Surg Br. 2010, 92:1481-8. 10.1302/0301-620X.92B11.25911

20. Harvie P, Chesser TJ, Ward AJ: The Bristol regional pelvic and acetabular fracture service: workload implications of managing the polytraumatised patient. Injury. 2008, 39:839-43. 10.1016/j.injury.2008.01.001

21. Aprato A, Joeris A, Tosto F, Kalampoki V, Stucchi A, Massè A: Direct and indirect costs of surgically treated pelvic fractures. Arch Orthop Trauma Surg. 2016, 136:325-30. 10.1007/s00402-015-2373-9

22. Christey G, Amey J, Campbell A, Smith A: Variation in volumes and characteristics of trauma patients admitted to a level one trauma centre during national level 4 lockdown for COVID-19 in New Zealand. N Z Med J. 2020, 133:81-88.

23. Rajput K, Sud A, Rees M, Rutka O: Epidemiology of trauma presentations to a major trauma centre in the North West of England during the COVID-19 level 4 lockdown. Eur J Trauma Emerg Surg. 2021, 47:631-6. 10.1007/s00068-020-01507-w

24. NOCA: Major Trauma Audit National Report 2016. (2016). Accessed: May 18, 2021: http://s3-eu-west1.amazonaws.com/noca-uploads/general/MAJOR_TRAUMA_AUDIT_NATIONAL_REPORT_2016_FINAL.pdf.

25. Meena UK, Tripathy SK, Sen RK, Aggarwal S, Behera P: Predictors of postoperative outcome for acetabular fractures. Orthop Traumatol Surg Res. 2013, 99:929-35. 10.1016/j.otsr.2013.09.004

26. Adebowale V, Alderson D, Burn W, et al.: Covid-19: call for a rapid forward looking review of the UK's preparedness for a second wave-an open letter to the leaders of all UK political parties. BMJ. 2020, 369:m2514. 10.1136/bmj.m2514

27. Emanuel EJ, Persad G, Upshur R, et al.: Fair allocation of scarce medical resources in the time of COVID-19 . N Engl J Med. 2020, 382:2049-55. 10.1056/NEJMsb2005114 